\title{
Rumah Susun Sewa dengan Pendekatan Arsitektur EKOLOGIS DI SURAKARTA
}

\author{
Andika Putra Perdana, Hadi Setyawan, Sri Yuliani \\ Program Studi Arsitektur \\ Jurusan Arsitektur Fakultas Teknik \\ Universitas Sebelas Maret Surakarta \\ Email :andika_deimonst@yahoo.com
}

\begin{abstract}
Planning and design of the Flats with Ecological Architecture approach is motivated by the density of settlements and slums along the Boro River,Jagalan Village, Surakarta. Density of existing settlements and slum area along the river resulted in environmental degradation and reduced Jagalan Village Green Open Space, because the settlement construction is done without regard to environmental conditions, resulting in an imbalance between natural and artificial environments. Environmental damage in the Village Jagalan then compounded by the behavior of people who dump waste in the river. Based on this phenomenon occurs due to lack of sufficient density residential land settlement and imbalance between the natural and the artificial environment characterized by reduced $R T H$ and flooding in Jagalan. The purpose of the planning and design of flats with Ecological Architecture approach is to accommodate the needs of residential Jagalan and create a balance between the environment and settlements. The approach used in the flats that takes into account the principles of planning and design of Ecology Architecture include: green buildings, building that responds to floods, waste water conservation so that waste water discharged into the river does not pollute the environment, saving energy by considering the direction of the wind and sun, and using recycled materials in the flats. The results of the planning and design of the Flats with Ecological Architecture approach is a dwelling that is in accordance with the needs of the community and environment friendly.
\end{abstract}

Keywords: A Flats, Ecology Architecture, Prone to flooding

\section{PENDAHULUAN}

Berdasarkan hasil survey ekonomi nasional 2004 BPS, menyebutkan bahwa 5,9 juta keluarga dari 55,0 juta keluarga belum memiliki tempat tinggal, sementara setiap tahunnya terjadi penambahan kebutuhan tempat tinggal sebanyak 820.000 unit rumah sehingga menyebabkan permasalahan ketersediaan lahan pemukiman di kota besar. Kekurangan tempat tinggal meningkat dari 5,8 juta unit pada tahun 2004 menjadi 7,4 juta unit pada tahun 2009. Diperkirakan terdapat sekitar 57.800 hektar perumahan dikategorikan sebagai hunian yang tidak layak huni. Sementara itu, 20,5 juta penduduk miskin kota menempati rumah yang tidak layak huni dan menyebabkan pembangunan perumahan baru masyarakat berpenghasilan rendah menjauh dari tempat kerja. Kondisi tersebut juga terjadi di Kota Surakarta, berdasarkan hasil survey dari Solo Kota Kita jumlah pemukiman di Kota Surakarta berjumlah 57\% dari luas Kota
Surakarta atau sekitar $2621 \mathrm{Ha}$, hal tersebut berbanding terbalik dengan jumlah Ruang Terbuka Hijau yang hanya $2 \%$ dari luas kota (lihat Gambar 1).
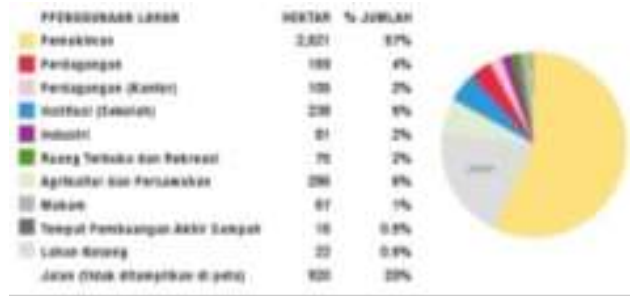

Gambar 1.Grafik Tata Guna Lahan Kota Surakarta (solokotakita.org, 2013)

Kondisi serupa juga dialami Kelurahan Jagalan yang merupakan salah satu dari lima kelurahan terpadat di Kota Surakarta. Kelurahan Jagalan memiliki total KK sebanyak 3497 KK dengan 605 KK di antaranya adalah warga miskin yang menempati hunian ilegal.Kelurahan Jagalan 
memiliki rumah tanpa sertifikat sebanyak 253 unit hunian.

Kondisi demikian menyebabkan kerusakan lingkungan di Kelurahan Jagalan, karena Warga Jagalan banyak yang mendirikan pemukiman di sepanjang sungai tanpa memperhatikan kondisi lingkungan di sekitarnya yang kemudian diperparah oleh prilaku masyarakat yang membuang limbah ke Sungai Boro, hal tersebut menyebabkan Kelurahan Jagalan menjadi salah satu kelurahan rawan banjir di Kota Surakarta.

Untuk mengatasi kurangnya lahan pemukiman serta berkurangnya lahan terbuka hijau dan kerusakan lingkungan akibat pembangunan pemukiman secara berlebihan tanpa memikirkan kondisi lingkungan, maka diperlukan sebuah rumah susun dengan menerapkan prinsip Arsitektur Ekologis yang memperhatikan kondisi lingkungan di sekitarnya agar tercipta keseimbangan antara rumah susun dengan lingkungannya.

\section{METODE}

Metode yang dilakukan untuk mencapai tujuan dan sasaran adalah metode pemrograman arsitektur yang terdiri dari gagasan awal, penelusuran dan rumusan permasalahan, pencarian data (referensi, preseden, dan teoritik), pengolahan data dan informasi, konsep perancangan (building performance concept) dan konsep perancangan (programing and design criteria), serta transformasi arsitektur.

\subsection{Temuan dan Penelusuran Masalah (Problem Finding)}

Penelusuran masalah dimulai dengan adanya fenomena atau isu kepadatan pemukiman dan pemukiman kumuh di sepanjang Sungai Boro Kelurahan Jagalan, Surakarta.Kepadatan pemukiman dan pemukiman kumuh yang ada di sepanjang sungai mengakibatkan penurunan kualitas lingkungan di Kelurahan Jagalan, karena pembangunan pemukiman dilakukan tanpa memperhatikan kondisi lingkungan sekitarnya sehingga menimbulkan ketidakseimbangan antara lingkungan alam dan lingkungan buatan yang kemudian diperparah oleh perilaku masyarakat yang membuang limbah ke sungai.Berdasarkan permasalahan tersebut kemudian timbul solusi desain untuk membuat rumah susun dengan pendekatan Arsitektur Ekologis.

\subsection{Temuan Konsep Perencanaan dan Perancangan}

Pemahaman tentang standar pembangunan rumah susun yang menerapkan prinsip Arsitektur Ekologi dikembangkan dengan adanya kajian pustaka: teoritik, preseden, dan pengetahuan empirik mengenai rumah susun dan Arsitektur Ekologis.

\subsection{Pendekatan dan Temuan Konsep Perencanaan}

Perumusan konsep perencanaan dilakukan dengan metode induktif, yaitu pendekatan berdasarkan fakta dan fenomena kepadatan pemukiman di Kelurahan Jagalan dan kerusakan lingkungan akibat pembangunan pemukiman secara berlebihan tanpa memperhatikan lingkungan dan metode deduktif, yaitu pendekatan berdasarkan teori yang membantu mengarahkan pembahasan sesuai dengan perencanaan rumah susun dengan pendekatan Arsitektur Ekologis. Cara yang digunakan adalah:

1. Analisis

Analisis perencanaan (building concept) mengidentifikasi masalah kepadatan pemukiman dan kerusakan lingkungan di Kelurahan Jagalan yang diselesaikan dengan memperhatikan prinsip perancangan Arsitektur Ekologis namun tetap memperhatikan kenyamanan dan kebiasaan warga Kelurahan Jagalan sebagai calon penghuni rumah susun.

Analisis Perancangan (building criteria) dilakukan dengan mengolah data yang telah terkumpul dan dikelompokan berdasarkan:

a. Pemrograman fungsional, bertujuan untuk mengidentifikasikan penggunaan rumah susun, di anataranya pelaku kegiatan, sifat kegiatan, sifat organisasi

b. Pemrograman performansi menerjemahkan secara sistematik kebutuhan para pengguna rumah susun dan fasilitasnya kedalam persyaratan kebutuhan ruang, persyaratan besaran ruang, serta penggunaan sistem bangunan yang sesuai dengan prinsip 
perencanaan dan perancangan Arsitektur Ekologis

c. Analisis arsitektural merupakan tahap penggabungan program fungsional dan performansi. Proses ini dilakukan dengan analisis pengolahan tapak yang sesuai dengan kondisi Kelurahan Jagalan yang rawan banjir dan mempertimbangkan aspek ekologi. Tampilan bangunan yang sesuai dengan kondisi lingkungan di dalam tapak, serta peruangan, utilitas, penggunaan material bekas, struktur dan sistem bangunan yang ekologis.

2. Sintesis

Tahap ini merupakan penggabungan referensi yang berupa teori maupun preseden dan hasil analisis fakta di lapangan sehingga didapatkan kesimpulan untuk mendapatkan konsep perancangan yang sesuai dan kemudian ditransformasikan ke bentuk ungkapan fisik yang dikehendaki sesuai dengan program fungsional, performansi, dan arsitektural.

\section{ANALISIS}

\subsection{Analisis Lokasi dan Tapak}

1. Tujuan :

Analisis tapak bertujuan untuk mendapatkan dan menentukan lokasi yang sesuai untuk rumah susun.

2. Dasar pertimbangan:

a. Terletak di tengah wilayah pengembangan kota dan sesuai dengan rencana peruntukan lahan kota yang diatur dalam RUTRK Kota Surakarta.

b. Berdasarkan pada PERDA Kota Surakarta No. 1 Tahun 2012, pasal 70 huruf a) : pengembangan rumah susun dilakukan di kawasan pusat kota dan kawasan lainnya yang terdapat kawasan pemukiman padat dan kumuh dengan tujuan untuk menambah RTH.

c. Tapak terletak dekat dengan pusat kota dan mudah diakses oleh penghuni dan pengunjung rumah susun

3. Proses Analisis

Berdasarkan pada dasar pertimbangan, lokasi rumah susun berada di Kelurahan Jagalan, Kota Surakarta. Hasil survey Solo
Kota Kita menyatakan bahwa, Kelurahan Jagalan merupakan salah satu kelurahan terpadat kelima di Kota Surakarta dengan tingkat kepadatan penduduk mencapai 191 jiwa/Ha, sedangkan pada SNI 03-17332004 menyatakan bahwa kawasan dengan kondisi kepadatan penduduk sudah mendekati atau melebihi 200jiwa/Ha disyaratkan untuk didirikan hunian bertingkat.

Kelurahan Jagalan merupakan salah satu kelurahan rawan banjir di Kota Surakarta dengan jumlah kerusakan bangunan akibat banjir mencapai 991 pemukiman, berdasarkan data dari Kelurahan Jagalan daerah rawan banjir di Kelurahan Jagalan berada di RW 03, 05, dan 15 dengan jumlah pemukiman yang tergenang mencapai 253 pemukiman yang semuanya merupakan pemukiman kumuh di tepi Sungai Boro.

Berdasarkan dasar pertimbangan dan analisis yang telah dilakukan maka tapak rumah susun berada di Kelurahan Jagalan RW 05 dekat dengan Sungai Boro (lihat Gambar 2)

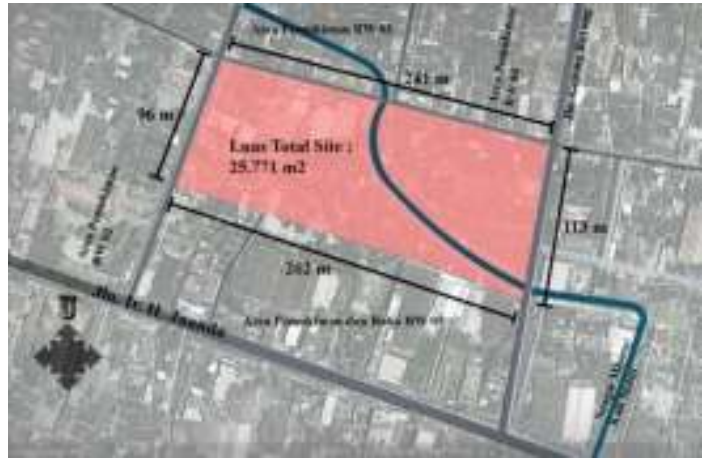

Gambar 2.Rencana Tapak Rumah Susun

\subsection{Analisis Pencapaian dan Sirkulasi}

1. Tujuan :

Analisis pencapaian dan sirkulasi bertujuan untuk menentukan letak main entrance dan side entrance pada rumah susun, serta untuk menentukan alur sirkulasi pejalan kaki dan kendaraan di dalam rumah susun.

2. Dasar Pertimbangan :

a. Nilai aksesibilitas dan kemudahan pencapaian ke dalam maupun ke luar tapak, baik untuk berbagai jenis kendaraan dan pejalan kaki. 
b. Kondisi dan potensi jalan di sekitar tapak.

3. Proses Analisis

Berdasarkan hasil survey yang telah dilakukan di dalam tapak maka ditetapkan main entrance berada di Jalan Gotong Royong (berada di sebelah timur tapak) yang merupakan jalan utama masuk ke dalam tapak dengan lebar jalan sekitar $8 \mathrm{~m}$, hal tersebut berdasarkan pertimbangan kemudahan akses penghuni dan pengunjung rumah susun untuk masuk ke dalam tapak.

Side entrance berada di jalan lingkungan/jalan kampung yang berada di sebelah utara dan timur tapak dengan pertimbangan agar tapak dapat diakses oleh warga sekitar.Diagram analisis pencapaian dan sirkulasi dapat dilihat pada Gambar 3.

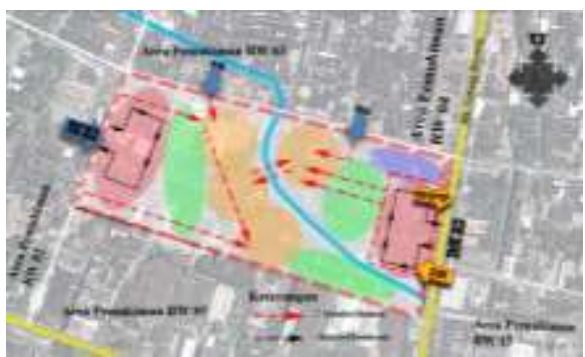

Gambar 3.Diagram Rencana Pencapaian dan Sirkulasi di dalam Tapak

\subsection{Anaisis Pengolahan Tapak}

1. Tujuan :

Menentukan rencana pengolahan tapak yang sesuai dengan kondisi lingkungan tapak dan memperhatikan prinsip Arsitektur Ekologi dalam perencanaannya.

2. Dasar Pertimbangan :

Hasil survey kondisi eksisting tapak, prinsip-prinsip Arsitektur Ekologi dalam perencanaan tapak.

3. Proses Analisis

Berdasarkan hasil survey kondisi eksisting tapak dan hasil analisis yang telah dilakukan sebelumnya, maka dapat disimpulkan bahwa pengolahan tapak pada perencanaan rumah susun terdiri dari :

a. Area parkir yang berada di bagian timur dan barat tapak dekat dengan main entrance dan side entrance dengan tujuan untuk mempermudah aksesibilitas penghuni dan pengunjung. Antara area parkir dan jalan pejalan kaki dipisahkan oleh pohon dan tanaman yang berfungsi untuk melindungi pejalan kaki sekaligus sebagai penghijauan jalan (Frick $\mathrm{H}$, Tri Hesti Mulyani, 2006). Gambar diagram taman pemisah antara jalur pejalan kaki dengan area parkir dapat dilihat pada Gambar 4.

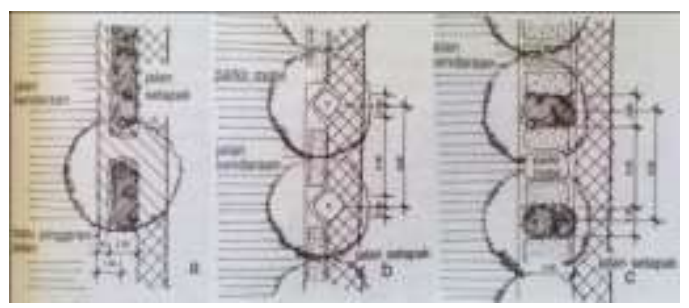

Gambar 4.Taman antara jalus pejalan kaki dengan area parkir

(Frick H, Tri Hesti Mulyani,2006)

b. Taman sebagai penghubung antara tempat parkir dan rumah susun, serta taman yang terletak di sepanjang Sungai Boro dapat dijadikan sebagai kebun sayur. Taman pada rumah susun berfungsi untuk menambah Ruang Terbuka Hijau (RTH) sehingga dapat meningkatkan bidang resapan tanah dan mengurangi banjir (Frick $\mathrm{H}$, Tri Hesti Mulyani, 2006). Taman pada area rumah susun dibuat lubang biopori yang berfungsi untuk mengatasi banjir, karena dengan membuat lubang biopori di taman sepanjang sungai maka air hujan atau air dari saluran pembuangan akan terserap sehinga jumlah air yang mengalir dijalan-jalan atau dipermukaan tanah akan berkurang.

c. Area ekonomi dan rumah susun terletak dekat dengan area parkir dan pemukiman warga kampung dengan tujuan agar memberikan kemudahan akses bagi penghuni dan pengunjung.

Diagram rencana pengolahan tapak dapat dilihat pada Gambar 5. 


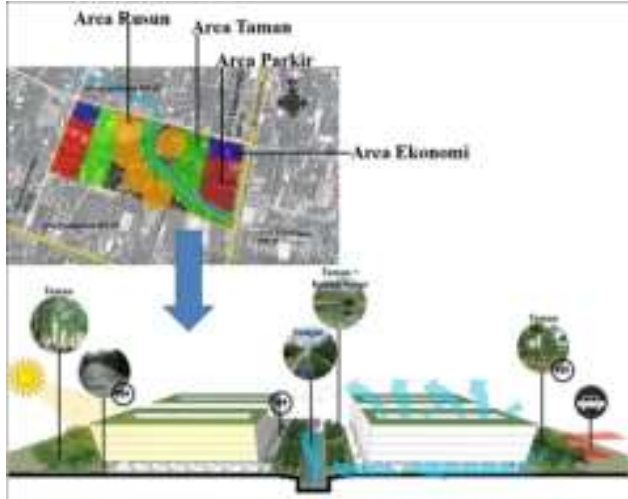

Gambar 5.Diagram Rencana Pengolahan Tapak

\subsection{Analisis Orientasi dan Bentuk Bangunan}

1. Tujuan:

Bertujuan untuk menentukan orientasi dan bentuk bangunan yang sesuai dengan kondisi eksisting serta mendapatkan tampilan bangunan yang sesuai dengan prinsip perancangan Arsitektur Ekologis.

2. Dasar Pertimbangan :

Kondisi eksisiting tapak, kondisi klimatologis tapak

3. Proses Analisis

a. Orientasi bangunan

Orientasi bangunan ditentukan berdasarkan kondisi klimatologi tapak. Berdasarkan hasil survey, pada pagi hingga sore hari tapak terus terkena cahaya matahari tanpa dibayangi oleh bangunan di sekitarnya karena luasan tapak yang mencapai $25.771 \mathrm{~m}^{2}$, sedangkan angin dengan intensitas tinggi bertiup dari arah barat daya site. Angin masuk dari arah jalan lingkungan yang langsung berhubungan dengan jalan raya Ir. $\mathrm{H}$. Juanda dan melewati area terbuka yang tidak terbangun pemukiman (lihat Gambar $6)$.

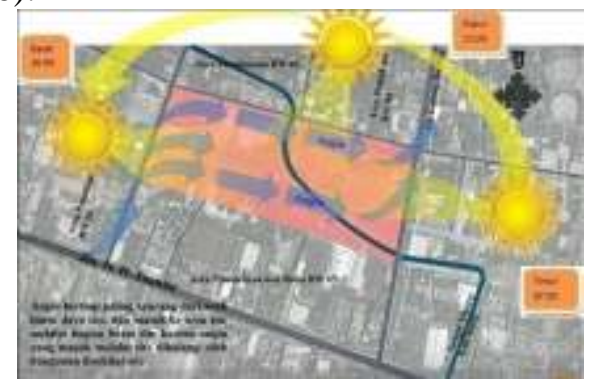

Gambar 6.Diagram Arah Angin dan Matahari pada Tapak
Berdasarkan kondisi eksisting tersebut maka direncanakan orientasi unit hunian pada rumah susun akan menghadap arah utara dan selatan tapak, hal ini dikarenakan arah angin masih dapat dibelokan sementara sinar matahari tidak, maka orientasi bangunan lebih diarahkan untuk mengantisipasi sinar matahari (Lippsmeier, 1999) selain itu juga bertujuan agar unit hunian tidak terkena cahaya matahari secara langsung yang dapat menimbulkan glare dan peningkatan suhu dalam ruang (lihat Lampiran 1).

b. Bentuk Bangunan

Mengacu pada pendapat Manurung (2012) bahwa kondisi klimatologi dapat mempengaruhi bantuk bangunan, maka berdasarkan kondisi arah matahari dan angin yang masuk ke dalam tapak didapatkan bentuk bangunan antara lain:

1) Bentuk bangunan yang ramping memungkinakan cahaya alami masuk ke dalam bangunan serta cahaya matahari dapat mencapai ruang-ruang di dalam berbagai sisi sehingga dapat menghemat penggunaan energi listrik (Manurung, 2012) lihat Lampiran 2.

2) Bentuk atap pada rumah susun ini akan menggunakan green roof, karena green roof dapatmengurangi suhu ruang dibawahnya dan menambah ruang terbuka hijau kota (Frick H, Tri Hesti Mulyani, 2006). Fungsi atap hijau atau green roof dapat dilihat pada Gambar 7.

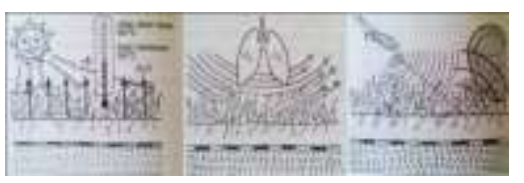

Gambar 7.Fungsi Atap Hijau pada Bangunan Rumah Susun

(Frick H, Tri Hesti Mulyani, 2006)

3) Memajukan fasade bangunan memungkinkan untuk bidang atau lantai diatasnya dapat berperan sebagai tritisan sehingga dapat menjadi penghalang cahaya 
matahari langsung dan mereduksi kemungkinan terjadinya silau bagi ruang dibawahnya (Manurung, 2012). Diagram penggunaan kantilever bangunan sebagai tritisan rumah susun dapat dilihat pada Gambar 11 di lampiran 3.

4) Menggunakan konsep rumah panggung dan menggunakan void yang besar untuk melancarkan sirkulasi udara ke dalam unit hunian. Konsep rumah panggung pad rumah susun dapat menjamin cross ventilation yang paling efisien(Frick H, Tri Hesti Mulyani, 2006), selain itu penggunaan rumah panggung pada rumah susun merupakan respon terhadap banjir yang terjadi pada tapak. Diagram sistem rumah panggung pada rumah susun dapat dilihat pada Gambar 8 .

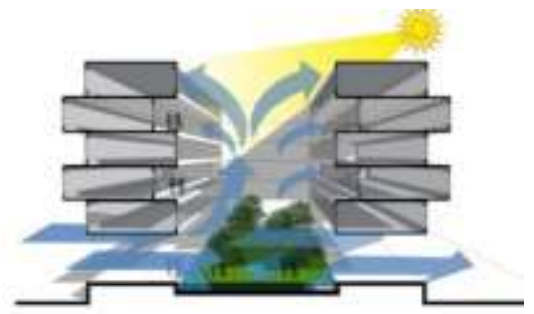

Gambar 8.Diagram Ilustrasi Konsep Rumah Panggung pada Rumah Susun

\section{KESIMPULAN (KONSEP DESAIN)}

Dari hasil analisa serta hasil korelasi yang dari beberapa data diatas, maka diperoleh hasil berupa :

Nama : Rumah Susun di Kelurahan Jagalan Lokasi : Jalan Gotong Royong, Kelurahan Jagalan, Surakarta

Luas Tapak: $25.771 \mathrm{~m}^{2}$

Konsep Arsitektur Ekologi yang diterapkan pada rumah susun antara lain:

1. Ruang Terbuka Hijau (RTH) sebesar $25 \%$ untuk memperbaiki kawasan RTH di dalam tapak dan Kelurahan Jagalan.

2. Menggunakan atap green roof. Atap green roof berfungsi untuk menurunkan suhu ruang di bawahnya, selain itu atap green roof dapat digunakan sebagai ruang berkumpul penghuni (lihat Gambar 9).

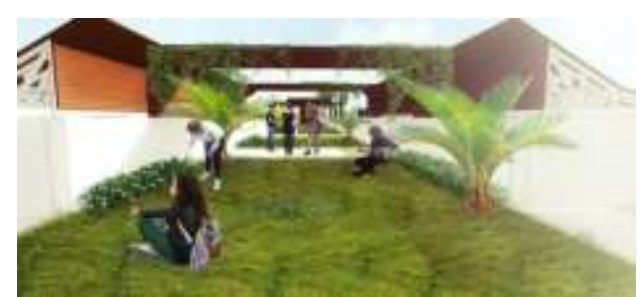

Gambar 9.Suasana Green Roof Rumah Susun

3. Menggunakan sistem pemurnian air limbah dan air hujan agar dapat digunakan kembali. Diagram sistem pemurnian air limbah pada rumah susun dapat dilihat pada Lampiran 4.

4. Orientasi unit hunian pada rumah susun menghadap utara dan selatan tapak dengan tujuan untuk menghindari cahaya matahari langsung yang dapat menyebabkan peningkatan suhu ruang dan efek glarepada ruang unit hunian (lihat Gambar 10).

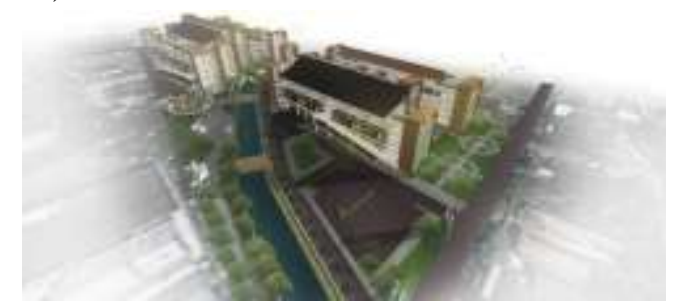

Gambar 10.Perspektif Kawasan Rumah Susun

5. Bentuk bangunan yang ramping.

Bentuk bangunan dibuat ramping dengan lebar bangunan $8 \mathrm{~m}$ tiap blok agar cahaya matahari dapat masuk ke dalam bangunan dari dua sisi bangunan, sehingga dapat menghemat energi pada rumah susun (lihat Gambar 11).

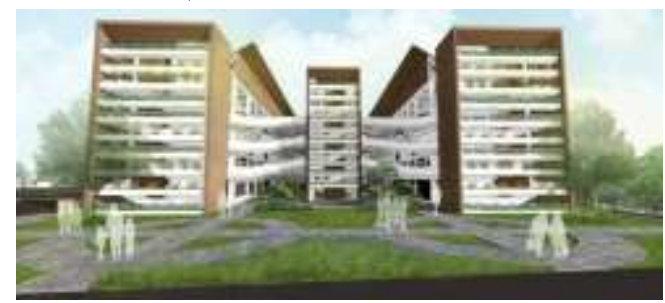

Gambar 11.Tampak Timur Rumah Susun

6. Menggunakan secondary skin yang dapat dibuka tutup pada unit hunian dengan tujuan agar cahaya matahari yang masuk 
ke dalam unit hunian dapat diatur intensitasnya.

\section{REFERENSI}

Frick H, Tri Hesti Mulyani. (2006). Arsitektur Ekologis . Penerbit Kanisius. Yogyakarta Lippsmeier, Georg. (1999). Bangunan Tropis. Jakarta. Erlangga

Manurung, Parmongan. (2012). Pencahayaan Alami dalam Arsitektur.Yogyakarta.ANDI

Sekretaris Daerah Kota Surakarta. (2012). Peraturan Daerah Kota Surakarta Nomor 1 Tentang Rencana Tata Ruang Wilayah Kota Surakarta Tahun 2011-2031. Surakarta

solokotakita.org (2013) 